\title{
Epoxidation of olefins using a novel synthesized tungsten dendritic catalyst
}

\author{
Eduardo G. Vieira ${ }^{a}$, Newton L. Dias Filho ${ }^{\text {a, b, * }}$ \\ a Departamento de Física e Química, Unesp-Univ Estadual Paulista, Av. Brasil, 56-Centro, Caixa Postal 31, 15385-000, Ilha Solteira, São Paulo, Brazil \\ ${ }^{\mathrm{b}}$ Universidade do Extremo Sul Catarinense, Av. Universitaria, 1105, CP 3167, CEP 88806-000, Criciúma, SC, Brazil
}

\section{H I G H L I G H T S}

- Synthesis and characterization of a novel dendritic macromolecule used as catalyst.

- Dendritic catalyst based on nanosilicate modified with methyl acrylate and ethylenediamine.

- The catalyst POSS-DG2.0-[W(CO $\left.)_{3} \mathrm{Br}_{2}\right]$ exhibits great activity.

\section{A R T I C L E I N F O}

\section{Article history:}

Received 1 September 2016

Received in revised form

28 July 2017

Accepted 11 August 2017

Available online 18 August 2017

\section{Keywords:}

Dendritic catalyst

Tungsten complex

Epoxidation

Olefins

\begin{abstract}
A B S T R A C T
In this work, we carry out the preparation and characterization of new dendritic catalyst from an oligomer polyhedral silsesquioxane core (POSS-DG2.0). This material was used in the immobilization of the $\left[\mathrm{W}(\mathrm{CO})_{3} \mathrm{Br}_{2}(\mathrm{NCMe})_{2}\right]$ complex for optimization of the synthesis of the new dendritic catalyst. To determine the reaction time, the temperature effect and the amount of groups anchored in the material $(\mathrm{mmol})$, some parameters, such as equilibration time and adsorption isotherms were studied. After the optimization studies and with the intention of application in catalysis, the new catalytic macromolecule was prepared by reaction of the dendrimer with the organometallic complex. The new catalyst was characterized by elemental analysis, FTIR, ${ }^{13} \mathrm{C}$ and ${ }^{29} \mathrm{Si}$ NMR, SEM, EDS, DRX and TGA. The new catalytic macromolecule POSS-DG2.0-[W(CO) $\left.{ }_{3} \mathrm{Br}_{2}\right]$ was tested in the epoxidation of olefins and proved to be an active catalyst with conversion rates between 60 and $88 \%$ and high selectivity in the formation of epoxides. To the best of our knowledge, this study is the first that has reported the preparation of POSSDG2.0-[W(CO) $\left.{ }_{3} \mathrm{Br}_{2}\right]$ for catalytic epoxidation of 1-octene, cyclooctene, (S)-limonene, cis-3-hexen-1-ol, trans-3-hexen-1-ol and styrene.
\end{abstract}

() 2017 Elsevier B.V. All rights reserved.

\section{Introduction}

The homogeneous catalysts have benefits over those heterogeneous, especially higher selectivity and yield $[1,2]$. Nonetheless, the facility of separation and recyclability of the catalysts in heterogeneous processes render these preferred by the industry [1]. The demand for heterogeneous catalysts that possess the advantages of both types remains a main issue of relevance. In order to improve catalytic processes of industrial relevance, such as the epoxidation of olefins, it is necessary to act at the level of the supports and the proper catalysts, organometallic molecules, as well as its process of

\footnotetext{
* Corresponding author. Universidade do Extremo Sul Catarinense, Av. Universitaria, 1105, CP 3167, CEP 88806-000, Criciúma, SC, Brazil.

E-mail address: nldias@unesc.net (N.L. Dias Filho).
}

anchoring (fixing) on surface to obtain robust catalysts and that are not easily leached. The reaction of olefin oxidation is fascinating because of its industrial importance in the production of resins, dyes, perfumes and surfactants [3-7]. This oxidation reaction is particularly important for chemical and pharmaceutical production, resulting in products such as alcohols, aldehydes, ketones, acids, epoxides, etc., that are intermediates in many organic syntheses $[4,5,7]$. To make the process of epoxidation more efficient, the use of the catalytic systems is necessary $[4,5]$.

In this work, the catalysis innovation is associated with the combination of supports based on nanosilica (POSS- Polyhedral oligomeric silsesquioxane) with the appropriate ligands and with the organometallic complexes introduced by various processes in these materials.

Polyhedral oligomeric silsesquioxanes (POSS) are organicinorganic hybrid macromolecules of the empirical formula 
$\left(\mathrm{RSiO}_{3 / 2}\right)_{\mathrm{n}}$, or $\mathrm{R}_{\mathrm{n}} \mathrm{T}_{\mathrm{n}}$ where $\mathrm{R}$ is an organic substituent, $\mathrm{n}=4,6,8$, $10,12,14,16,18$ which continue to interest researchers worldwide because they allow for a wide variety of applications in several areas [8-10]. POSS compounds have hybrid architectures, which have a nucleus, also called a "cube" because of their cubic structure, with skeleton consisting of silicon and oxygen atoms $\left(\mathrm{SiO}_{1.5}\right) \mathrm{x}$, which is externally substituted by polar structures or organic functional groups $[11,12]$. The octahedral structures of the empirical formula $\left(\mathrm{RSiO}_{3 / 2}\right)_{8}$ offer a unique advantage, forming spherically symmetric dendrimers possessing rapid growth of the molecular weight by means of the eight functionalized groups in the core. These materials can be referred to as "POSS-Dendrimers" (POSS-DG2.0) [13,14].

Therefore, in an octafunctionalized silsesquioxane, such as $\left(\mathrm{SiO}_{3 / 2}\right)_{8}$, the degree of functionalization can reach approximately $8 \mathrm{mmol}$ of functionalized groups. In one dendrimer with double arms, the degree of functionalization may be double, i.e., about $16 \mathrm{mmol}$. In a dendrimer with triple arms will reach the triple, and consequently.

Dendrimers are a class of exceptional macromolecules with a regular, monodisperse, and highly branched three-dimensional architecture [15]. They consist of a central core and branched monomers [16]. The spherical shape of these macromolecules permits the functionalization of a large number of surface groups in their structure $[15,17]$.

Thus the goal of this paper is the synthesis of a new dendritic catalyst from an oligomer polyhedral silsesquioxane core. In order to optimize the synthesis process, a study of the immobilization of the $\left[\mathrm{W}(\mathrm{CO})_{3} \mathrm{Br}_{2}(\mathrm{NCMe})_{2}\right]$ complex on the dendrimer surface with core of silsesquioxane was done. Furthermore, this work searches for heterogeneous catalysts that combine the great selectivity and other advantages of homogeneous catalysts. The new dendritic catalyst POSS-DG2.0-[W(CO) $\left.{ }_{3} \mathrm{Br}_{2}\right]$ was applied in catalytic tests of epoxidation of 1-octene (1-oct), cyclooctene (Cy8), (S)-limonene (Slim), cis-3-hexen-1-ol (cis-3), trans-3-hexen-1-ol (trans-3) and styrene (Sty).

\section{Investigational procedures}

\subsection{Additional information}

The chemicals were purchased from Sigma-Aldrich.

All solvents used in this study were previously purified, unless otherwise indicated. The complex $\left[\mathrm{W}(\mathrm{CO})_{3} \mathrm{Br}_{2}(\mathrm{NCMe})_{2}\right]$ was prepared according to literature methods, but with modifications [18]. The infrared analyses were obtained using a Nicolet 5DXB Instruments spectrometer. The analysis of nuclear magnetic resonance of carbon and silicon were performed on a Bruker Avance 400 spectrometer in the chemical institute of Araraquara/SP. The electronic scanning microscopy images were taken in an EVO LS15 Carl Zeiss and coated with gold.

Energy dispersive spectroscopy (EDS). The EDS spectra were obtained by Oxford Instruments - Inca X-act with resolution of $133 \mathrm{eV}$.

The X-ray diffractograms were obtained by Ragaku Miniflex instrument, operating at $30 \mathrm{kV}$ and $15 \mathrm{~mA}$ using nickel filter and $\mathrm{Cu}$ radiation (Ka) and a wavelength of $1.5418 \AA$.

A Mass spectrometry with inductively coupled plasma (ICP-MSSeries X 2 - Thermo Scientific) was used in this paper.

\subsection{Synthesis of POSS-DG2.0-[W(CO $\left.)_{3} B_{2}\right]$ catalyst}

The POSS-DG2.0-[W(CO $\left.)_{3} \mathrm{Br}_{2}\right]$ was prepared based on the study of the $\left[\mathrm{W}(\mathrm{CO})_{3} \mathrm{Br}_{2}(\mathrm{NCMe})_{2}\right]$ immobilization on POSS-DG2.0, using the following procedure:
The rigid dendrimer core was synthetized in a reaction flask using $4 \mathrm{~L}$ (98.87 mol) of methanol, $535 \mathrm{~mL}$ (about $17.31 \mathrm{~mol}$ ) of hydrochloric acid and $207 \mathrm{~mL}(0.88 \mathrm{~mol})$ of 3aminopropyltriethoxysilane (APTS). The solution was stirred for six weeks forming the POSS-PrNH${ }_{3}^{+} \mathrm{Cl}^{-}$. The white solid phase formed was filtered and washed giving a $47 \%$ yield. Then, $30 \mathrm{~g}$ $(0.025 \mathrm{~mol})$ of POSS-PrNH${ }_{3}^{+} \mathrm{Cl}^{-}$was added to a methanol solution containing $17.18 \mathrm{~g}(0.020 \mathrm{~mol})$ of sodium bicarbonate in a $500 \mathrm{~mL}$ flask under stirring for $48 \mathrm{~h}$ in an atmosphere of nitrogen at room temperature. Next, $98.85 \mathrm{~mL}$ (1.091 mol) of methyl acrylate (MA) was added and the solution was maintained under stirring for $48 \mathrm{~h}$ at $50{ }^{\circ} \mathrm{C}$. Then, water was added forming a precipitate, which was filtered and washed successively with water resulting in a pasty material denominated POSS-DG0.5. Next, a suspension of $25 \mathrm{~g}$ $(0.010 \mathrm{~mol})$ of POSS-DG0.5 and $22.28 \mathrm{~mL}(0.333 \mathrm{~mol})$ of ethylenediamine (EDA) was added to $250 \mathrm{~mL}(6.18 \mathrm{~mol})$ of methanol and stirred for 3 days at room temperature. The product denominated POSS-DG1.0 was separated by means of a rotary evaporator at $50{ }^{\circ} \mathrm{C}$ under vacuum and recrystallized with ethyl acetate.

The material denominated POSS-DG1.5 (20 g, $\left.3 \times 10^{-3} \mathrm{~mol}\right)$ was synthesized starting from POSS-DG1.0 by a procedure similar to the preparation of POSS-DG0.5.

The material denominated POSS-DG2.0 (15 g, $\left.2 \times 10^{-3} \mathrm{~mol}\right)$ was synthesized starting from POSS-DG 1.5 by a procedure similar to the preparation of POSS-DG1.0.

The complex $\left[\mathrm{W}(\mathrm{CO})_{3} \mathrm{Br}_{2}(\mathrm{NCMe})_{2}\right]$ was prepared according to literature [18,19]. POSS-DG2.0 $\left(2.5 \mathrm{~g}, 3.9 \times 10^{-4} \mathrm{~mol}\right)$ was added to a solution of $\left[\mathrm{W}(\mathrm{CO})_{3} \mathrm{Br}_{2}(\mathrm{NCMe})_{2}\right]\left(1.98 \mathrm{~g}, 3.9 \times 10^{-3} \mathrm{~mol}\right)$ in pure ethanol $(50 \mathrm{~mL})$ under nitrogen, and the system was shaken at $50{ }^{\circ} \mathrm{C}$ over $12 \mathrm{~h}$. Then, the solvent was eliminated by filtration in inert atmosphere and the new catalyst was washed four times with dichloromethane and ethanol and hence dried, gave $2.42 \mathrm{~g}$ of POSSDG2.0-[W(CO $\left.)_{3} \mathrm{Br}_{2}\right]$ (Yield: $96.8 \% \mathrm{~m} / \mathrm{m}$ ).

\subsection{Study of immobilization of $\left[\mathrm{W}(\mathrm{CO})_{3} \mathrm{Br}_{2}(\mathrm{NCMe})_{2}\right]$ on POSS- DG2.0}

\subsubsection{Equilibrium time}

In this optimization, $150 \mathrm{mg}$ of POSS-DG2.0 was thoroughly mixed into $50 \mathrm{~mL}$ of a solution containing the organometallic complex solution with concentration of $1.0 \times 10^{-2} \mathrm{~mol} / \mathrm{L}$ in ethanol and shaken for $40 \mathrm{~min}$ at $70 \mathrm{rpm}$. The time study was conducted from 5 to $40 \mathrm{~min}$.

\subsubsection{Isotherms of sorption}

The maximum capacity was investigated at $25{ }^{\circ} \mathrm{C}$ by batch immobilization process under nitrogen atmosphere. Nearly $150 \mathrm{mg}$ of the material was added in $50 \mathrm{~mL}$ of $\left[\mathrm{W}(\mathrm{CO})_{3} \mathrm{Br}_{2}(\mathrm{NCMe})_{2}\right]$ solution with concentrations between 0.001 and $0.01 \mathrm{~mol} / \mathrm{L}$ and shaken for 25 min. The amount of the organometallic complex was determined by ICP-MS.

\subsubsection{Temperature effect}

Temperature effect were conducted at the temperatures of $25-65^{\circ} \mathrm{C}$ under nitrogen atmosphere, maintaining continuous the level of the complex, the amount of sorbent and the time in $50 \mathrm{~mL}$, $150 \mathrm{mg}$ and $25 \mathrm{~min}$, respectively.

\subsection{Chromatographic parameters}

The analyses were obtained through a gas chromatograph coupled in a mass selective detector (Thermo Scientific) using fused silica capillary column. The chromatographic parameters developed were: 


\subsubsection{1-Octene}

Ion source temperature: $200{ }^{\circ} \mathrm{C}$; Detector Gain: $1 \times 10^{5}$; Molecular mass rate: $20-120 \mathrm{~g} / \mathrm{mol}$, Full scan mode; Oven Heating Ramp: The oven temperature was programmed from $60{ }^{\circ} \mathrm{C}$ (maintained for $2 \mathrm{~min}$ ) to $200{ }^{\circ} \mathrm{C}$ (held for $1 \mathrm{~min}$ ) at a rate of $50^{\circ} \mathrm{C} /$ min; Injector temperature: The temperature of the injector was set at $250{ }^{\circ} \mathrm{C}$ operated in splitless mode, Carrier gas flow: Helium was used as carrier gas at constant pressure mode ( $70 \mathrm{kPa}$ ); Transfer line temperature: $280{ }^{\circ} \mathrm{C}$.

\subsubsection{Cyclooctene and styrene}

Ion source temperature: $200{ }^{\circ} \mathrm{C}$; Detector Gain: $1 \times 10^{5}$; Molecular mass rate: $20-130 \mathrm{~g} / \mathrm{mol}$, Full scan mode; Oven Heating Ramp: The oven temperature was programmed from $60{ }^{\circ} \mathrm{C}$ (maintained for $1 \mathrm{~min}$ ) at $200{ }^{\circ} \mathrm{C}$ (held for $1 \mathrm{~min}$ ) at a rate of $40{ }^{\circ} \mathrm{C} /$ min; Injector temperature: The temperature of the injector was set at $250{ }^{\circ} \mathrm{C}$ operated in splitless mode; Carrier gas flow: Helium was used as carrier gas at constant pressure mode (100 kPa); Transfer line temperature: $280^{\circ} \mathrm{C}$.

\subsubsection{Limonene}

Ion source temperature: $200{ }^{\circ} \mathrm{C}$; Detector Gain: $1 \times 10^{5}$; Molecular mass rate: $20-150 \mathrm{~g} / \mathrm{mol}$, Full scan mode; Oven Heating Ramp: The oven temperature was programmed from $60^{\circ} \mathrm{C}$ (held for $2 \mathrm{~min}$ ) at $200{ }^{\circ} \mathrm{C}$ (held for $2 \mathrm{~min}$ ) at a rate of $30^{\circ} \mathrm{C} / \mathrm{min}$; Injector temperature: The temperature of the injector was set at $250{ }^{\circ} \mathrm{C}$ operated in splitless mode for all used olefins; Carrier gas flow: Helium was used as carrier gas at constant pressure mode (80 kPa); Transfer line temperature: $280^{\circ} \mathrm{C}$.

\subsubsection{Cis-3-hexen-1-ol and trans-3-hexen-1-ol}

Ion source temperature: $200^{\circ} \mathrm{C}$; Detector Gain: $1 \times 10^{5}$; Molecular mass rate: $20-100 \mathrm{~g} / \mathrm{mol}$, Full scan mode; Oven Heating Ramp: The oven temperature was programmed from $60{ }^{\circ} \mathrm{C}$ (maintained for $42 \mathrm{~s}$ ) $200^{\circ} \mathrm{C}$ (held for $2 \mathrm{~min}$ ) at a rate of $100^{\circ} \mathrm{C} / \mathrm{min}$; Injector temperature: The temperature of the injector was set at $250{ }^{\circ} \mathrm{C}$ operated in splitless mode; Carrier gas flow: Helium was used as carrier gas at constant pressure mode (110 kPa); Transfer line temperature: $280{ }^{\circ} \mathrm{C}$.

\subsubsection{Catalytic studies}

POSS-DG2.0-[W(CO) $\left.{ }_{3} \mathrm{Br}_{2}\right]$ was tested in the epoxidation of 1octene, cyclooctene, limonene, cis-3-hexen-1-ol, trans-3-hexen-1ol and styrene, using tertbutyl hydroperoxide (TBHP) as oxidant at $55{ }^{\circ} \mathrm{C}$ under air atmosphere. The reactions were performed in a container with magnetic stirring and, to prevent the evaporation of the dichloromethane, a condenser was used $[7,18,19]$. In each case, the container was loaded with the substrate, dibutyl ether as internal standard (DBE), heterogeneous catalyst, dichloromethane and tertbutyl hydroperoxide $[2,20,21]$.

Substrate: $13.7 \times 10^{-3} \mathrm{~mol}$ of 1-Octene $(1.53 \mathrm{~g}, 2.14 \mathrm{~mL})$, cyclooctene (1.51 g, $1.78 \mathrm{~mL})$, (S)-limonene (1.86 g, $2.20 \mathrm{~mL})$, cis-3hexen-1-ol (1.37 g, $1.61 \mathrm{~mL})$, trans-3-hexen-1-ol (1.37 g, $1.67 \mathrm{~mL})$ and styrene ( $1.42 \mathrm{~g}, 1.56 \mathrm{~mL}$ ); thus the same amount in moL of each olefin was used; dibutyl ether (internal standard); $3 \mathrm{~mL}$ of dichloromethane $\left(\mathrm{CH}_{2} \mathrm{Cl}_{2}\right)$; Catalysts: $0.2 \mathrm{~g}\left(0.137 \times 10^{-3} \mathrm{~mol}\right)$ of the heterogeneous catalyst; Oxidant: $27.4 \times 10^{-3} \mathrm{~mol}$ of TBHP (5.0-6.0 M in decane) (2.47 g, $2.65 \mathrm{~mL}$ ) for 1-Octene, cyclooctene, (S)-limonene, cis-3-hexen-1-ol, trans-3-hexen-1-ol and styrene.

The reactions were initiated with the addition of the oxidant agent (TBHP). The samples were collected every 20 min during the first hour, then every $2 \mathrm{~h}$ until the eighth hour and the last in the 24 th hour of reaction $[7,20,21]$. To disable the oxidant agent, manganese dioxide was added in each collected sample. The resulting viscous material was separated by filtration and a micro aliquot of the supernatant was injected into the GC-MS. The conversion of each substrate was evaluated by formation of their respective epoxides in a GC-MS using the previously developed methods. Epoxidation test without a metal catalyst was investigated and no catalytic activity was observed [7,20,21]. The conversion rate after $24 \mathrm{~h}, \mathrm{TOF}$ (turnover frequencies) after $20 \mathrm{~min}$ and the selectivity for each detected product were calculated.

\section{Results and discussion}

\subsection{Synthesis of the heterogeneous catalyst POSS-DG2.0- $\left[\mathrm{W}(\mathrm{CO})_{3} \mathrm{Br}_{2}\right]$}

The core of the dendrimer, POSS-PrNH${ }_{3}^{+} \mathrm{Cl}^{-}$, was synthesized by the hydrolytic condensation reaction of the 3-aminopropyltriethoxysilane precursor [22,23]. The hydrolysis reaction of the alkoxides produces the monomer containing the silanol function $(\mathrm{Si}-\mathrm{OH})$, whereas the condensation reaction of silanol groups produces bond $\mathrm{Si}-\mathrm{O}-\mathrm{Si}$ and water and alcohol as subproducts $[22,23]$. Consequently, after the preparation of the core, such as reported previously, the synthesis of dendrimer was completed by Michael's addition reaction between methyl acrylate and ethylenediamine [24,25]. The synthesis of the new dendrimer catalyst was performed by the reaction of POSS-DG2.0 with the complex $\left[\mathrm{W}(\mathrm{CO})_{3} \mathrm{Br}_{2}(\mathrm{NCMe})_{2}\right]$ in ethanol solution (Scheme 1).

POSS-DG2.0-[W(CO) ${ }_{3} \mathrm{Br}_{2}$ ]: $\mathrm{Si}_{8} \mathrm{O}_{78} \mathrm{C}_{282} \mathrm{H}_{544} \mathrm{~N}_{104} \mathrm{Br}_{12} \mathrm{~W}_{6}$ (8917.54 $\mathrm{g} / \mathrm{mol}$ ): calculated C $37.94 \%, \mathrm{~N} 16.32 \%, \mathrm{H} 6.10 \%$, W $12.38 \%$; found C $37.62 \%, \mathrm{~N} 16.08 \%, \mathrm{H} 5.89 \%$, W 12.01\%. POSS-DG2.0-[W(CO) $\left.{ }_{3} \mathrm{Br}_{2}\right]$ contained $12.01 \%$ of tungsten. This value proposes that six tungsten complex are bound to the POSS-DG2.0-[W(CO) $\left.)_{3} \mathrm{Br}_{2}\right]$ (Scheme 1).

The FTIR spectrum of POSS-DG2.0-[W(CO) $\left.{ }_{3} \mathrm{Br}_{2}\right]$ (Fig. 1) shows the existence of peaks with different intensities. The band in $1132 \mathrm{~cm}^{-1}$ is assigned to $\mathrm{Si}-\mathrm{O}-\mathrm{Si}$ [26], this band proves the stability of the material even after several steps of reaction. Two strong absorptions centered at 1641 and $1564 \mathrm{~cm}^{-1}$ are assigned to the $\mathrm{C}=\mathrm{O}$ stretching (amide $\mathrm{I}$ ) and $\mathrm{N}-\mathrm{H}$ bending $/ \mathrm{C}-\mathrm{N}$ stretching (amide II) vibrations of the POSS-DG2.0-[W(CO) $\left.{ }_{3} \mathrm{Br}_{2}\right]$ [26]. The bands around 3423 and $3251 \mathrm{~cm}^{-1}$ of primary amine, proves the incorporation external with ethylenediamine. The stretching $\mathrm{C} \equiv \mathrm{O}$ vibrations appear as very intense absorptions at 2001, 1888 and $1787 \mathrm{~cm}^{-1}$, indicating the coordination of the $\mathrm{W}(\mathrm{CO})_{3} \mathrm{Br}_{2}$ fragment on dendrimer [20-22,27].

The ${ }^{13} \mathrm{C}$ NMR solid-state spectrum of POSS-DG2.0-[W(CO) $\left.)_{3} \mathrm{Br}_{2}\right]$ (Fig. 2) shows carbon signals of the propyl chain at 10.64 $\left(\mathrm{SiCH}_{2} \mathrm{CH}_{2}\right)(1), 20.83\left(\mathrm{CH}_{2}-\mathrm{CH}_{2}-\mathrm{CH}_{2}\right)(2)$, and $33.32 \mathrm{ppm}\left(\mathrm{CH}_{2}-\mathrm{N}-\right)$ (3). The peaks at $39.03\left(\mathrm{~N}-\underline{\mathrm{CH}}_{2}-\mathrm{CH}_{2}\right)(4), 59.12\left(\mathrm{~N}-\mathrm{CH}_{2}-\mathrm{CH}_{2}\right)(5)$ and $174.18(\mathrm{O}-\mathrm{C}=\mathrm{O})(6)$ regions appear due to the incorporation of the two methyl acrylate molecules per nitrogen atoms [14,26]. On the other hand, the peaks in $53.54\left(\mathrm{NH}-\mathrm{CH}_{2}-\mathrm{CH}_{2}-\mathrm{NH}_{2}\right)$ (7) and $50.68 \mathrm{ppm}\left(\mathrm{NH}-\mathrm{CH}_{2}-\mathrm{CH}_{2}-\mathrm{NH}_{2}\right)$ (8) arose after the reaction with ethylenediamine $[14, \overline{26}]$.

After reaction with $\left[\mathrm{W}(\mathrm{CO})_{3} \mathrm{Br}_{2}(\mathrm{NCMe})_{2}\right]$ the new catalyst (POSS-DG2.0-[W(CO) $\left.)_{3} \mathrm{Br}_{2}\right]$ ) does not display the resonance peak of the carbon atoms of the carbonyl groups due to the absence of the proton [21].

The ${ }^{29} \mathrm{Si}$ NMR solid-state spectrum of POSS-DG2.0-[W(CO $\left.)_{3} \mathrm{Br}_{2}\right]$ (Fig. 3) show a signal at $-67.58 \mathrm{ppm}$, which comes in the range observed for the same compound by other authors $[23,24,28,29]$. This single resonance peak confirms that even after successive reactions the core of the dendrimer remains intact.

The image of the heterogeneous catalyst (Fig. 4) presents an agglomerated surface [30] and it can be beneficial when dealing with heterogeneous catalysts, facilitating their separation and recycling.

In the spectrum of EDS of POSS-DG2.0-[W(CO) $\left.)_{3} \mathrm{Br}_{2}\right]$ (Fig. 5) two 


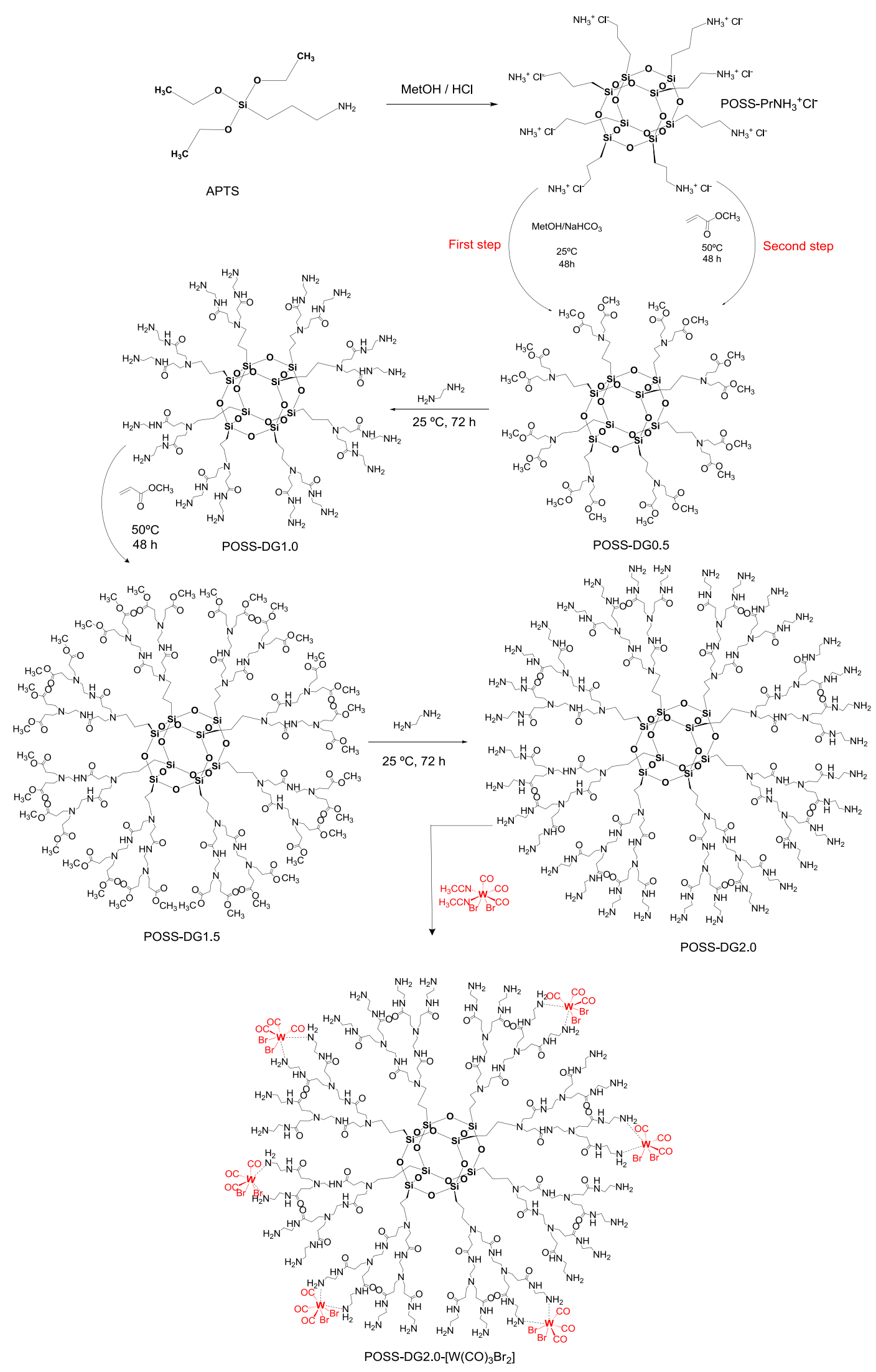

Scheme 1. Synthesis of POSS-DG2.0-[W(CO $\left.)_{3} \mathrm{Br}_{2}\right]$. 


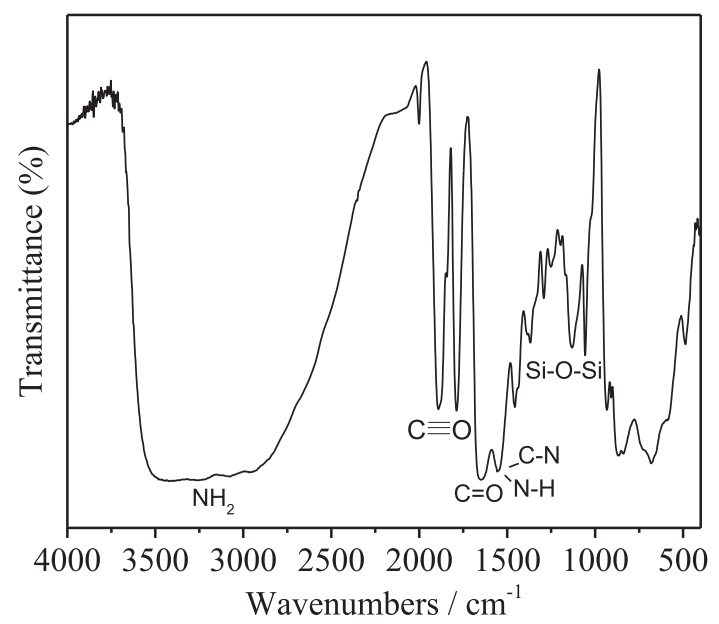

Fig. 1. FTIR spectrum of POSS-DG2.0-[W(CO $\left.)_{3} \mathrm{Br}_{2}\right]$.

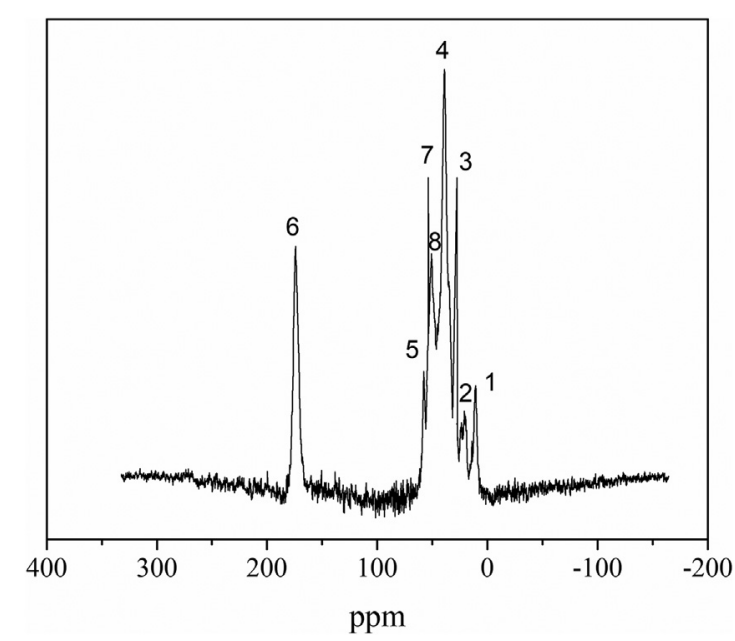

Fig. 2. ${ }^{13} \mathrm{C}$ NMR spectrum of POSS-DG2.0-[W(CO) $\left.{ }_{3} \mathrm{Br}_{2}\right]$.

peaks are noted, concerning to tungsten and bromine derived from the tungsten complex. Furthermore, the peaks of silicon, oxygen, carbon and nitrogen remain intact, proving the thermal and mechanical stability of the precursor.

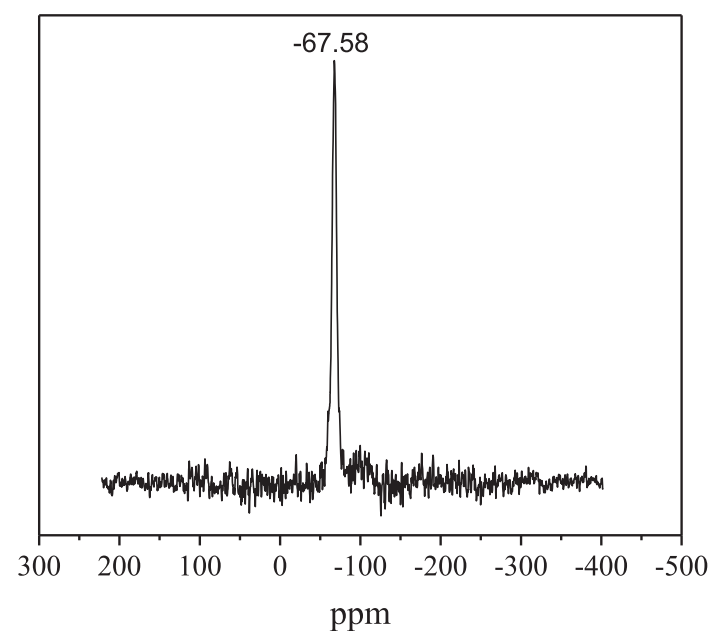

Fig. 3. ${ }^{29} \mathrm{Si}$ NMR spectrum of POSS-DG2.0-[W(CO $\left.)_{3} \mathrm{Br}_{2}\right]$.

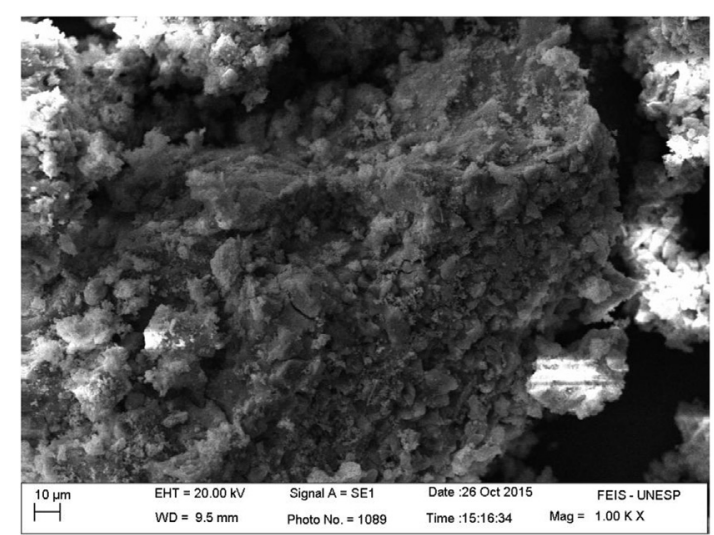

Fig. 4. SEM image of the POSS-DG2.0-[W(CO) $\left.{ }_{3} \mathrm{Br}_{2}\right]$ catalyst.

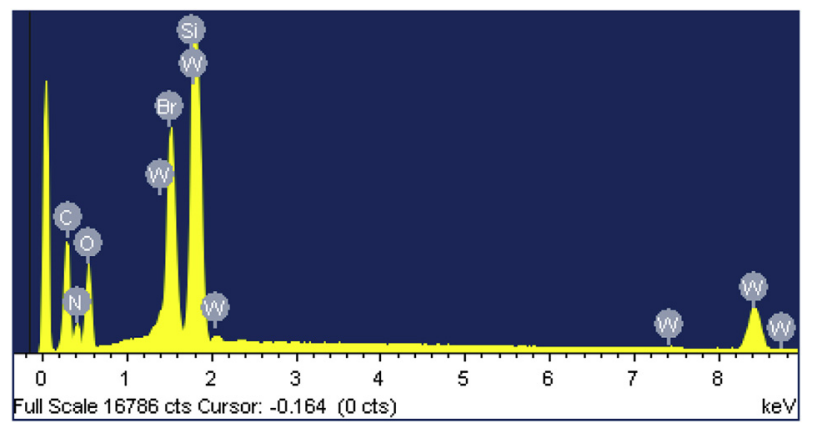

Fig. 5. EDS spectrum of the POSS-DG2.0-[W(CO) $\left.{ }_{3} \mathrm{Br}_{2}\right]$ catalyst.

After the reaction of the precursor material with the complex $\left[\mathrm{W}(\mathrm{CO})_{3} \mathrm{Br}_{2}(\mathrm{NCMe})_{2}\right]$, the X-ray diffractogram exhibited three major peaks at $7.40^{\circ}, 23.94^{\circ}$ and $53.64^{\circ}$ (Fig. 6). The presence of three peaks confirms the incorporation of organometallic complex on the surface of the dendrimer.

The POSS-DG2.0-[W(CO) $\left.{ }_{3} \mathrm{Br}_{2}\right]$ catalyst displays good thermal stability because of the presence of a POSS core. As shown in Fig. 7, the first mass loss occurs up to $115{ }^{\circ} \mathrm{C}$ regarding the loss of water. The second mass loss of the catalyst begins from $164{ }^{\circ} \mathrm{C}$ to about $475^{\circ} \mathrm{C}$ and refers to the disintegration of external generations of

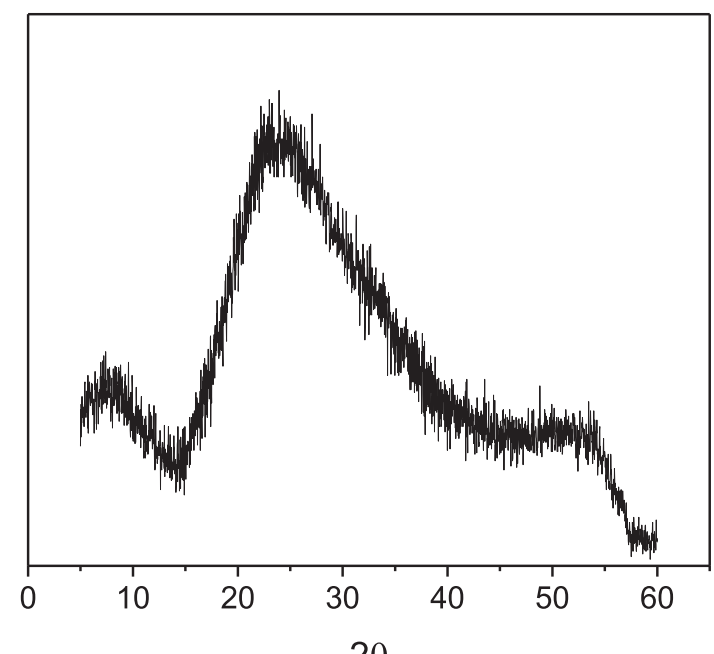

Fig. 6. X-ray diffractogram of the POSS-DG2.0-[W(CO) $\left.{ }_{3} \mathrm{Br}_{2}\right]$ catalysts. 


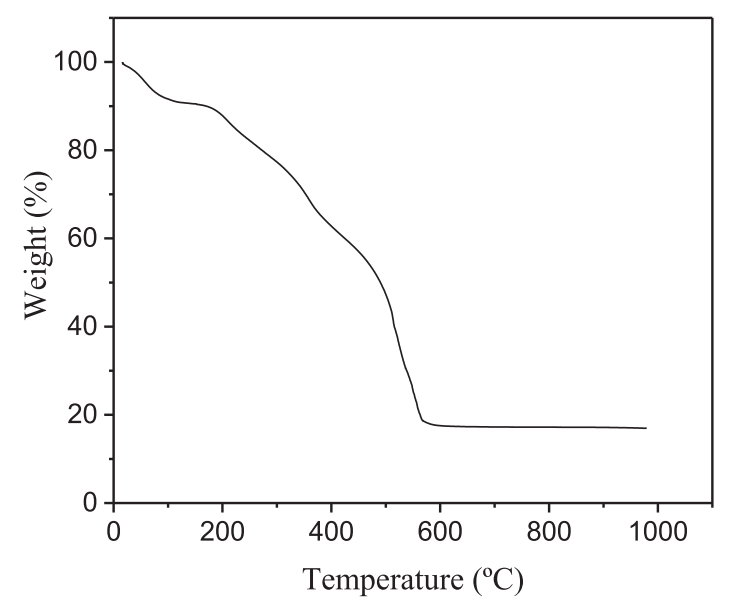

Fig. 7. Thermogravimetric curve of the POSS-DG2.0- $\left[\mathrm{W}(\mathrm{CO})_{3} \mathrm{Br}_{2}\right]$ catalyst.

the dendrimer. The third mass loss occurs from $475{ }^{\circ} \mathrm{C}$ to about $552{ }^{\circ} \mathrm{C}$ and is related to the burning of the propyl amino arm of the POSS core. After the complete burning of POSS-DG2.0-[W(CO) $\left.{ }_{3} \mathrm{Br}_{2}\right]$ the percentage of $17.44 \%$ refers to the inorganic part of the core and of the immobilized complex.

\subsection{Sorption isotherms}

Sorption experiments such as adsorbent dosage, equilibrium time and adsorption isotherm were studied to optimize the synthesis process of the new catalyst.
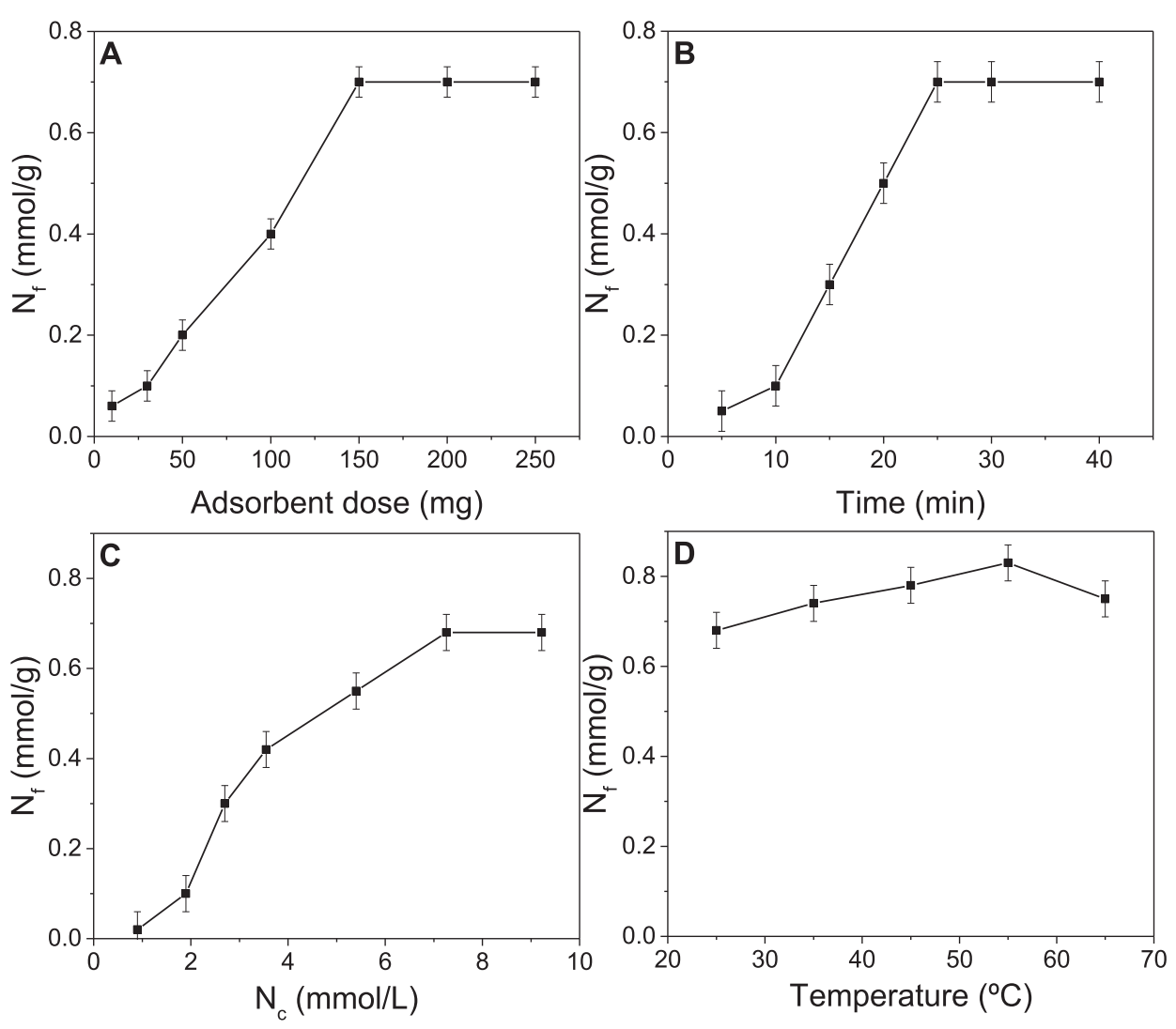
to the number of vacant sites [31-33]. presented in Fig. $8 \mathrm{C}$.

\subsubsection{Applications of isotherm models}

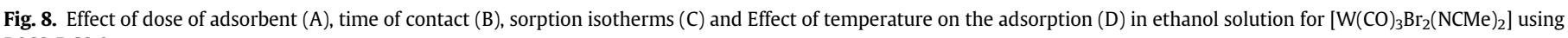
POSS-DG2.0.

The adsorbent dosage on the immobilization of $\left[\mathrm{W}(\mathrm{CO})_{3} \mathrm{Br}_{2}\right.$ $(\mathrm{NCMe})_{2}$ ] in ethanol solution was investigated and the result was shown in Fig. 8A. It is evident that the sorption equilibrium increases by increasing of the mass of materials. This occurs because as the amount of sorbent increases there is an increase in surface area and adsorption sites until the adsorbed amount is equivalent

The immobilization of $\left[\mathrm{W}(\mathrm{CO})_{3} \mathrm{Br}_{2}(\mathrm{NCMe})_{2}\right]$ complex by sorption on POSS-DG2.0 amplified with time, reaching the highest value in $25 \mathrm{~min}$, and subsequently it remained constant, as presented in Fig. 8B. It is evident that the shaking time for the POSS-DG2.0 achieves the equilibrium depended of the initial concentration of the complex. The adsorption capacity of the POSS-DG2.0 in immobilization of the complex $\left[\mathrm{W}(\mathrm{CO})_{3} \mathrm{Br}_{2}(\mathrm{NCMe})_{2}\right]$ was rapid in the first $20 \mathrm{~min}$, becoming slower with the increase time of contact.

To investigate the sorption capacity, a concentration range of $\left[\mathrm{W}(\mathrm{CO})_{3} \mathrm{Br}_{2}(\mathrm{NCMe})_{2}\right]$ in ethanol solution was shaken for $30 \mathrm{~min}$, using $150 \mathrm{mg}$ of sorbent at $25^{\circ} \mathrm{C}$. The maximum sorption capacity value for $\left[\mathrm{W}(\mathrm{CO})_{3} \mathrm{Br}_{2}(\mathrm{NCMe})_{2}\right]$ using POSS-DG2.0 was $0.70 \mathrm{mmol} \mathrm{g}^{-1}$. The sorption isotherm of the metallic complex is

To evaluate the influence of temperature, the sorption experiments were performed in different temperatures $(25,35,45,55$ and $65{ }^{\circ} \mathrm{C}$ ). In Fig. 8D, the adsorption process was favoured with increasing temperature, which demonstrates that the adsorption of the complex is an endothermic process [34], while at temperatures above $60{ }^{\circ} \mathrm{C}$ there is a decrease in the sorption capacity of the complex due to the onset of the degradation of organic groups.

From Fig. 8C it was possible to apply the isotherm models such 
Table 1

Isotherm parameters for sorption of $\left[\mathrm{W}(\mathrm{CO})_{3} \mathrm{Br}_{2}(\mathrm{NCMe})_{2}\right]$ in ethanol at $25{ }^{\circ} \mathrm{C}$ using POSS-DG2.0 as sorbent.

\begin{tabular}{|c|c|c|c|}
\hline Models & Equations & Parameters & {$\left[\mathrm{W}(\mathrm{CO})_{3} \mathrm{Br}_{2}(\mathrm{NCMe})_{2}\right]$} \\
\hline Langmuir & $\mathrm{N}_{\mathrm{c}} / \mathrm{N}_{\mathrm{f}}=\mathrm{N}_{\mathrm{c}} / \mathrm{N}_{\mathrm{f}}^{\max }+1 /\left(\mathrm{N}_{\mathrm{f}}^{\max } \mathrm{b}\right)$ & $\begin{array}{l}\mathrm{N}_{\mathrm{f}}(\mathrm{mmol} / \mathrm{g}) \\
\mathrm{b}(\mathrm{L} / \mathrm{mmol}) \\
\mathrm{R}_{\mathrm{L}} \\
\mathrm{R}^{2}\end{array}$ & $\begin{array}{l}0.67 \\
8.6 \times 10^{3} \\
0.11 \\
0.993\end{array}$ \\
\hline Freundlich & $\ln N_{f}=\ln N_{f}+\left((1 / n) \ln N_{c}\right.$ & $\begin{array}{l}\mathrm{n}(\mathrm{mol} / \mathrm{L}) \\
\mathrm{K}_{\mathrm{F}}(\mathrm{mmol} / \mathrm{g}) \\
\mathrm{R}^{2}\end{array}$ & $\begin{array}{l}25.85 \\
6.22 \\
0.937\end{array}$ \\
\hline Temkin & $\mathrm{N}_{\mathrm{f}}=\mathrm{B} \ln \mathrm{A}+\mathrm{B} \ln \mathrm{N}_{\mathrm{c}}$ & $\begin{array}{l}\mathrm{A}(\mathrm{L} / \mathrm{mmol}) \\
\mathrm{B} \\
\mathrm{R}^{2}\end{array}$ & $\begin{array}{l}36.85 \\
5.785 \\
0.948\end{array}$ \\
\hline D-R & $\ln N_{f}=\left(\ln N_{f}^{\max }\right)-\left(B_{1} \varepsilon^{2}\right)$ & $\begin{array}{l}\mathrm{N}_{\mathrm{f}}^{\max }(\mathrm{mmol} / \mathrm{g}) \\
\mathrm{B}_{1} \\
\mathrm{E}(\mathrm{Kj} / \mathrm{mol}) \\
\mathrm{R}^{2}\end{array}$ & $\begin{array}{l}0.44 \\
1 \times 10^{-3} \\
22.36 \\
0.965\end{array}$ \\
\hline
\end{tabular}

Table 2

Kinetic sorption parameters obtained using pseudo-first-order, pseudo-second-order, and Elovich models for $\left[\mathrm{W}(\mathrm{CO})_{3} \mathrm{Br}_{2}(\mathrm{NCMe})_{2}\right]$

\begin{tabular}{|c|c|c|c|c|c|c|c|c|c|c|}
\hline \multirow{2}{*}{\multicolumn{2}{|c|}{ Equations }} & \multicolumn{3}{|c|}{ Pseudo-first-order } & \multicolumn{3}{|c|}{ Pseudo-second-order } & \multicolumn{3}{|l|}{ Elovich } \\
\hline & & \multicolumn{3}{|c|}{$\ln \left(\mathrm{N}_{\mathrm{f}}-\mathrm{N}_{\mathrm{t}}\right)=\ln \mathrm{N}_{\mathrm{f}}-\left(\mathrm{K}_{1} / 2.303\right) \mathrm{t}$} & \multicolumn{3}{|c|}{$\mathrm{t} / \mathrm{N}_{\mathrm{t}}=1 /\left(\mathrm{K}_{2} \mathrm{~N}_{\mathrm{f}}^{2}\right)+\left(1 / \mathrm{N}_{\mathrm{f}}\right) \mathrm{t}$} & \multicolumn{3}{|c|}{$\mathrm{N}_{\mathrm{t}}=1 /(\beta \ln (\alpha \beta))+1 /(\beta \ln \mathrm{t})$} \\
\hline Sorbent & $\mathrm{N}_{\mathrm{f}}^{\exp }(\mathrm{mmol} / \mathrm{g})$ & $\mathrm{N}_{\mathrm{f}}^{\max }(\mathrm{mmol} / \mathrm{g})$ & $K_{1}\left(\min ^{-1}\right)$ & $R^{2}$ & $\begin{array}{l}\mathrm{N}_{\mathrm{f}}^{\max } \\
(\mathrm{mmol} / \mathrm{g})\end{array}$ & $K_{2}\left(\min ^{-1}\right)$ & $R^{2}$ & $\begin{array}{l}\alpha \\
(\mathrm{mmol} / \mathrm{gmin})\end{array}$ & $\begin{array}{l}\mathrm{B} \\
(\mathrm{g} / \mathrm{mmol})\end{array}$ & $R^{2}$ \\
\hline POSS-DG2.0 & 0.70 & 0.15 & $7.6 \times 10^{-3}$ & 0.922 & 0.72 & 9.547 & 0.998 & 7.215 & 3.251 & 0.975 \\
\hline
\end{tabular}

as Langmuir [35], Freundlich [33,36], Temkin [37] and DubininRadushchevich (D-R) [38]. The theoretical data for each model are listed in Table 1 . The determination factor $\left(R^{2}\right)$ of Langmuir showed an excellent adjust the experimental data.

Langmuir model highlights that the immobilization of the $\left[\mathrm{W}(\mathrm{CO})_{3} \mathrm{Br}_{2}(\mathrm{NCMe})_{2}\right]$ complex was in monolayers (homogeneous). It was also verified that the value of $R_{L}$ was lesser than 1 indicating that the anchoring of $\left[\mathrm{W}(\mathrm{CO})_{3} \mathrm{Br}_{2}(\mathrm{NCMe})_{2}\right]$ was favourable.

The parameter $n$ greater than 1 (Frendlich model) reflects an immobilization in multi-layered (heterogeneous) of the organometallic complex.

D-R model says that the anchoring of the $\left[\mathrm{W}(\mathrm{CO})_{3} \mathrm{Br}_{2}(\mathrm{NCMe})_{2}\right]$ was achieved by chemisorption. Taking into account the values of the determination factors $\left(R^{2}\right)$ it is notable that the best fitting order of the experimental data was Langmuir $>\mathrm{D}-\mathrm{R}>$ Temkin $>$ Freundlich.

The values of pseudo-first-order, pseudo-second-order and Elovich [39-41] are given in Table 2. Pseudo-second order model was the most suitable and its determination factor was 0.998 .

Some thermodynamic parameters [42] are in Table 3. The $-\Delta G$ showed the spontaneous nature of immobilization of complex on the surface of POSS-DG2.0. The $+\Delta H$ revealed that the immobilization was endothermic. The $+\Delta S$ resulted from the increased randomness due to the sorption of organometallic complex.

Table 3

Thermodynamic parameters for $\left[\mathrm{W}(\mathrm{CO})_{3} \mathrm{Br}_{2}(\mathrm{NCMe})_{2}\right]$ in ethanol.

\begin{tabular}{|c|c|c|c|c|}
\hline \multirow[t]{2}{*}{ Sorbent } & \multirow[t]{2}{*}{$\mathrm{t}^{*}\left({ }^{\circ} \mathrm{C}\right)$} & \multirow{2}{*}{$\begin{array}{l}\Delta \mathrm{G}^{\circ} \\
\frac{(\mathrm{KJ} / \mathrm{mol})}{\Delta \mathrm{G}=-\mathrm{RT} \operatorname{lnb}}\end{array}$} & $\begin{array}{l}\Delta \mathrm{S}^{\circ} \\
\left(\mathrm{J} / \mathrm{mol} \mathrm{k}^{-1}\right)\end{array}$ & $\begin{array}{l}\Delta \mathrm{H}^{\circ} \\
(\mathrm{KJ} / \mathrm{mol})\end{array}$ \\
\hline & & & \multicolumn{2}{|c|}{$\ln K_{1}=(\Delta S / R)-(\Delta \mathrm{H} /(\mathrm{RT})$} \\
\hline POSS-DG2.0 & $\begin{array}{l}25 \\
35 \\
45 \\
55 \\
65\end{array}$ & $\begin{array}{l}-55.059 \\
-56.912 \\
-58.765 \\
-60.618 \\
-\end{array}$ & 185.284 & 154.896 \\
\hline
\end{tabular}

\section{Catalytic properties}

The activities of the POSS-DG2.0-[W(CO) $\left.{ }_{3} \mathrm{Br}_{2}\right]$ as a catalyst for the oxidation of olefins were studied for 1-octene, cyclooctene, (S)limonene, cis-3-hexen-1-ol, trans-3-hexen-1-ol and styrene, with tert-butyl hydroperoxide (TBHP) as the oxygen source, at $55{ }^{\circ} \mathrm{C}$ in air atmosphere and $3 \mathrm{~mL}$ of dichloromethane as solvent. In Fig. 9 the dynamic of epoxidation of the olefins 1-octene (1-oct), cyclooctene (Cy8), (S)-limonene (S-lim), cis-3-hexen-1-ol (cis-3), trans3-hexen-1-ol (trans-3) and styrene (Sty) is shown in the presence of the heterogeneous catalyst (POSS-DG2.0-[W(CO) $\left.{ }_{3} \mathrm{Br}_{2}\right]$ ). Fig. 9 also shows that the maximum conversion times were obtained in a short period. S-lim, Cy8 and Sty require a time of 2, 1 and $1 \mathrm{~h}$, respectively. However, 1 -oct, cis-3 and trans-3 require a period of 4-6 h. Though the necessary period to produce the active species is different in each occasion, analogous catalytic species can be originated $[21,43]$.

Therefore, the results presented in Table 4 show that the

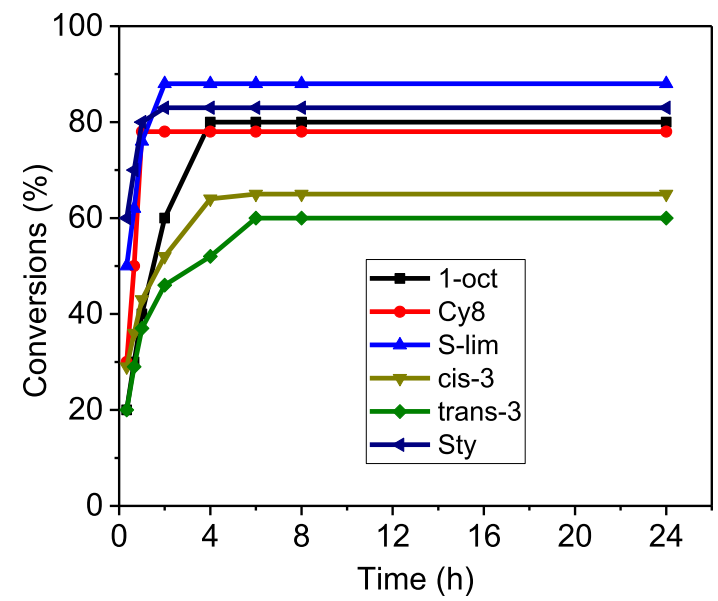

Fig. 9. Epoxidation dynamic of each olefin using POSS-DG2.0- $\left[\mathrm{W}(\mathrm{CO})_{3} \mathrm{Br}_{2}\right]$ as catalyst. 
Table 4

Conversions, Turnover Frequencies (TOF) and selectivity for catalytic epoxidation of olefins.

\begin{tabular}{|c|c|c|c|c|c|}
\hline Catalytic precursor & Substrate & $\begin{array}{c}\text { Conversion }^{\mathrm{a}}(\%) \\
1 \text { Cycle }\end{array}$ & $\mathrm{TOF}^{\mathrm{b}}$ & Selectivity (\%) & Products \\
\hline \multirow{11}{*}{ POSS-DG2.0-W } & 1-octene & 80 & 68 & $\begin{array}{c}5 \\
95\end{array}$ & $\begin{array}{c}\text { 1,2-Epoxyoctane } \\
\text { 1-Octanal }\end{array}$ \\
\hline & cyclooctene & 78 & 65 & 100 & Epoxide \\
\hline & (S)-limonene & 88 & 118 & 60 & Z-Lim-Epox \\
\hline & & & & 30 & E-Lim-Epox \\
\hline & & & & 2 & Z-Lim-OH \\
\hline & & & & 3 & E-Lim-OH \\
\hline & & & & 2 & Lim- $(\mathrm{OH})_{2}$ \\
\hline & & & & 3 & Dioxide \\
\hline & cis-3-hexen-1-ol & 65 & 47 & 100 & Epoxide \\
\hline & trans-3-hexen-1-ol & 60 & 50 & 100 & Epoxide \\
\hline & styrene & 83 & 91 & 100 & Epoxide \\
\hline
\end{tabular}

${ }^{\mathrm{a}}$ First Cycle of conversion at $24 \mathrm{~h}$.

b In units of mol (mol of $\mathrm{W})^{-1} \mathrm{~h}^{-1}$.

heterogeneous catalyst in question has a great conversion and TOF and shows the oxidation selectivity of the olefins 1-octene and (S)limonene. The four substrates, cyclooctene, cis-3-hexen-1-ol, trans3-hexen-1-ol and styrene are selectively oxidized to their epoxide without formation of diols. However, in the oxidation of 1-octene are detected two products referred to as 1-octanal and 1,2epoxyoctane. POSS-DG2.0-[W(CO) $\left.{ }_{3} \mathrm{Br}_{2}\right]$ has an extraordinary selectivity for formation of 1,2-epoxyoctane, $95 \%$ versus $5 \%$ for the formation of 1 -octanal, but the conversion is $80 \%$.

The oxidation of $(\mathrm{S})$-limonene results in the formation of several products (Table 4) and six of them were identified by gas chromatograph coupled to a mass spectrometer (GC-MS): Isomers of

Table 5

Comparison of the conversion capacities of POSS-DG2.0-[W(CO)3Br2] with others catalysts.

\begin{tabular}{|c|c|c|c|c|}
\hline Catalysts & Olefins & Conversions $^{\mathrm{a}}$ & $\mathrm{TOF}^{\mathrm{b}}$ & Ref. \\
\hline$\left[\mathrm{Cu}_{2}\left(\mathrm{~L}^{1}\right) \mathrm{Cl}_{3}\right] \cdot 2 \mathrm{H}_{2} \mathrm{O}$ & Sty & 72 & 10 & {$[44]$} \\
\hline$\left[\mathrm{Cu}_{2}\left(\mathrm{~L}_{2}\right)\left(\mathrm{N}_{3}\right) \mathrm{Cl}_{2}\right]$ & Sty & 75 & 10.4 & [44] \\
\hline cis-dioxomolybdenum(VI) & Cy8 & 75 & - & {$[45]$} \\
\hline cis-(CO) $)_{4} \mathrm{~W}$ (bipy) & Cy8 & 46 & - & {$[46]$} \\
\hline $\mathrm{MCM}-\left[\mathrm{WBr}_{2}(\mathrm{CO})_{3}\left(\mathrm{C}_{2} \mathrm{H}_{3} \mathrm{~N}_{3} \mathrm{~S}\right)_{2}\right]$ & 1 -oct & 10.4 & 2 & [21] \\
\hline Cube-C1 & (S)-lim & 53.7 & 14 & {$[21]$} \\
\hline $\mathrm{MCM}-\left[\mathrm{WBr}_{2}(\mathrm{CO})_{3}\left(\mathrm{C}_{2} \mathrm{H}_{3} \mathrm{~N}_{3} \mathrm{~S}\right)_{2}\right]$ & (S)-lim & 3.1 & 3 & [21] \\
\hline$\left[\mathrm{CpMo}(\mathrm{CO})_{2}(\operatorname{ImPyMes}) \mathrm{Cl}\right]$ & 1 -oct & 75 & - & {$[47]$} \\
\hline$\left[\mathrm{W}(\mathrm{CO})_{3} \mathrm{Br}_{2}(\mathrm{NCMe})_{2}\right]$ & $(S)-\lim$ & 21 & 16 & Present study \\
\hline POSS-DG2.0-[W(CO $\left.)_{3} \mathrm{Br}_{2}\right]$ & 1 -oct & 80 & 68 & Present study \\
\hline POSS-DG2.0-[W(CO) $\left.{ }_{3} \mathrm{Br}_{2}\right]$ & Cy8 & 78 & 65 & Present study \\
\hline POSS-DG2.0- $\left[\mathrm{W}(\mathrm{CO})_{3} \mathrm{Br}_{2}\right]$ & (S)-lim & 88 & 118 & Present study \\
\hline POSS-DG2.0-[W(CO $\left.)_{3} \mathrm{Br}_{2}\right]$ & cis-3 & 65 & 47 & Present study \\
\hline POSS-DG2.0-[W(CO $\left.)_{3} \mathrm{Br}_{2}\right]$ & trans -3 & 60 & 50 & Present study \\
\hline POSS-DG2.0-[W(CO $\left.)_{3} \mathrm{Br}_{2}\right]$ & Sty & 83 & 91 & Present study \\
\hline
\end{tabular}

a Percentage (\%).

b In units of $\mathrm{mol}(\mathrm{mol} \text { of } \mathrm{W})^{-1} \mathrm{~h}^{-1}$.

Table 6

Recycling studies performed over POSS-DG2.0-[W(CO) $\left.{ }_{3} \mathrm{Br}_{2}\right]$ catalyst.

\begin{tabular}{llll}
\hline Catalyst & & \multicolumn{2}{l}{$(S)$-limonene } \\
POSS-DG2.0-[W(CO $\left.)_{3} \mathrm{Br}_{2}\right]$ & & Conversion $(\%)$ & Selectivity to epoxide (\%) \\
\hline $1^{\circ}$ cycle & 88 & $93^{\mathrm{a}}$ \\
$2^{\circ}$ cycle & 83 & $90^{\mathrm{b}}$ \\
$3^{\circ}$ cycle & 82 & $90^{\mathrm{c}}$ \\
$4^{\circ}$ cycle & 82 & $92^{\mathrm{d}}$ \\
$5^{\circ}$ cycle & 83 & $92^{\mathrm{e}}$ \\
\hline
\end{tabular}

Z-lim-Epox, E-lim-Epox and dioxide.

Z-lim-Epox and E-lim-Epox. (+)-limonene-1,2-epoxide (Z-lim-Epox and E-lim-Epox), isomers of cyclohexen-1-ol-2-methyl-5-(1-methylethenyl) (Z-lim-OH and Elim-OH), (1S,2S,4R)-(+)-Limonene-1,2-diol $\left(\lim (\mathrm{OH})_{2}\right)$ and dipentene dioxide (dioxide). This amount of products and by-products are due to the existence of double bonds between carbon in the structure of the (S)-limonene.

As can be seen, the (S)-limonene has a strong selectivity for oxidation of the double bond between carbons, yielding the Z-limEpox, E-lim-Epox and dioxide isomers. POSS-DG2.0-[W(CO) $\left.{ }_{3} \mathrm{Br}_{2}\right]$ shows a selectivity for epoxide of $93 \%$ (Table 4 ).

Table 5 shows the comparison with other types of catalysts in the epoxidation of olefins. As can be seen, the POSS-DG2.0$\left[\mathrm{W}(\mathrm{CO})_{3} \mathrm{Br}_{2}\right]$ made a similar conversions or better than other types of catalysts. These results show that the present heterogeneous catalyst has higher conversion and TOF values than homogeneous and heterogeneous catalysts of different types and conditions.

Metal leaching studies were also performed by reusing the recovered POSS-DG2.0-[W(CO) $\left.{ }_{3} \mathrm{Br}_{2}\right]$ in five cycles. After the first cycle the solid was separated, washed with dichloromethane and dried at $50{ }^{\circ} \mathrm{C}$ for reuse, this was done at the end of each cycle. As can be seen in Table 6 , there was a reduction in the catalytic activity of the first to the second cycle, however, the other cycles tend to remain constant. ICP-MS analysis was used to determine the percentage of tungsten leached out into the liquid mixture during reactions. The $\mathrm{W}$ loading after five reaction cycles is about $98 \%$ of the starting value. The leaching of some weakly anchored tungsten complex present in the original catalyst may account for the initial low loss of activity.

\section{Conclusions}

The results of the characterization techniques allowed to prove that the preparation of the new dendritic macromolecule from an oligomer polyhedral silsesquioxane core (POSS-DG2.0) and of the catalytic macromolecule POSS-DG2.0-[W(CO $\left.)_{3} \mathrm{Br}_{2}\right]$ was successful.

The study of immobilization of $\left[\mathrm{W}(\mathrm{CO})_{3} \mathrm{Br}_{2}(\mathrm{NCMe})_{2}\right]$ complex was of fundamental importance to optimize the synthesis of the catalyst.

POSS-DG2.0-[W(CO) $\left.{ }_{3} \mathrm{Br}_{2}\right]$ shows a selectivity for epoxide of $100 \%$ for cyclooctene, cis-3-hexen-1-ol, trans-3-hexen-1-ol and styrene, and $95 \%$ for 1 -octene and $93 \%$ for (S)-limonene.

S-lim, Cy8 and Sty require a maximum conversion time of 2, 1 and $1 \mathrm{~h}$, respectively. On the other hand, cis-3 and trans-3 require a period of 4-6 h.

The dendritic catalyst has shown to have a good catalytic activity in the epoxidation of all olefins in all studies, but with special attention to limonene in which has $88 \%$ conversion and very low 
leaching.

\section{Conflict of interest statement}

The authors declare no competing financial interest.

\section{Acknowledgments}

Newton Luiz Dias Filho is grateful for the financial support by the FAPESP-Fundação de Amparo à Pesquisa do Estado de São Paulo (Grant no 2013/24602-0), and the CNPq-Conselho Nacional de Desenvolvimento Científico e Tecnológico (Grant no 306265/20133 and 448168/2014-6). Eduardo G. Vieira thanks FAPESP-Fundação de Amparo à Pesquisa do Estado de São Paulo (Grant no 2014/ 05566-5) for scholarships awarded. Newton Luiz Dias Filho and Eduardo G. Vieira acknowledge Professor Enes Furlani Junior, of the Department of plant science, food technology and social economy of Unesp-FEIS by analysis of ICP-MS and GC-MS.

\section{References}

[1] N.L. Dias Filho, F.C.M. Portugal, J.M.F. Nogueira, P. Brandão, V. Félix, P.D. Vaz, C.D. Nunes, L.F. Veiros, M.J.V. de Brito, M.J. Calhorda, An oligosilsesquioxane cage functionalized with molybdenum (II) organometallic fragments, Organometallics 31 (2012) 4495-4503.

[2] E.G. Vieira, I.V. Soares, N.C. da Silva, S.D. Perujo, D.R. do Carmo, N.L. Dias Filho, Synthesis and characterization of 3-[(thiourea)-propyl]-functionalized silica gel and its application in adsorption and catalysis, New J. Chem. 37 (2013) 1933-1943.

[3] Z. Li, S. Wu, H. Ding, D. Zheng, J. Hu, X. Wang, Q. Huo, J. Guan, Q. Kan, Immobilized $\mathrm{Cu}(\mathrm{II})$ and $\mathrm{Co}(\mathrm{II})$ salen complexes on graphene oxide and their catalytic activity for aerobic epoxidation of styrene, New J. Chem. 37 (2013) $1561-1568$.

[4] H. Ding, G. Wang, M. Yang, Y. Luan, Y. Wang, X. Yao, Novel sea urchin-like polyaniline microspheres-supported molybdenum catalyst: preparation, characteristic and functionality, J. Mol. Catal. A Chem. 308 (2009) 25-31.

[5] A.H. Haines, Methods for the Oxidation of Organic Compounds, Academic Press, New York, 1985.

[6] Q.H. Xia, H.Q. Ge, C.P. Ye, Z.M. Liu, K.X. Su, Advances in homogeneous and heterogeneous catalytic asymmetric epoxidation, Chem. Rev. 105 (2005) 1603-1662.

[7] S.M. Islam, A.S. Roy, P. Mondal, M. Mubarak, S. Mondal, D. Hossain, S. Banerjee, S.C. Santra, Synthesis, catalytic oxidation and antimicrobial activity of copper(II) Schiff base complex, J. Mol. Catal. A Chem. 336 (2011) 106-114.

[8] P.D. Lickiss, F. Rataboul, Fully condensed polyhedral oligosilsesquioxanes (POSS): from synthesis to application, in: Robert West (Ed.), Advances in Organometallic Chemistry, Advances in Organometallic Chemistry, Anthony F. Hill and Mark J. Fink, vol. 57, Elsevier Inc., The Netherlands, 2008, pp. 1-116.

[9] R.H. Baney, M. Itoh, A. Sakakibara, T. Suzuki, Silsesquioxanes, Chem. Rev. 95 (1995) 1409-1430.

[10] A. Provatas, M. Luft, J.C. Mu, A.H. White, J.G. Matisons, B.W. Skelton, Silsesquioxanes: Part I: a key intermediate in the building of molecular composite materials, J. Organomet. Chem. 565 (1998) 159-164.

[11] G. Li, L. Wang, H. Ni, C.U.J. Pittman, Polyhedral oligomeric silsesquioxane (POSS) polymers and copolymers: a review, J. Inorg. Organomet. Polym. Mater 11 (2001) 123-154.

[12] Y. Ni, S. Zheng, K. Nie, Morphology and thermal properties of inorganicorganic hybrids involving epoxy resin and polyhedral oligomeric silsesquioxanes, Polymer 45 (2004) 5557-5568.

[13] B. Hong, T.P.S. Thoms, H.J. Murte, M.J. Lebrun, Highly branched dendritic macromolecules with core polyhedral silsesquioxane functionalities, Inorg. Chem. 36 (1997) 6146-6147.

[14] K. Naka, M. Fujita, K. Tanaka, Y. Chujo, Water-soluble anionic POSS-core dendrimer: synthesis and copper(II) complexes in aqueous solution, Langmuir 23 (2007) 9057-9063.

[15] D.A. Tomalia, H. Baker, J.R. Dewald, M. Hall, G. Kallos, S. Martin, J. Roeck, J. Ryder, P. Smith, A new class of polymers: starburst-dendritic macromolecules, Polym. J. 17 (1985) 117-132.

[16] D.A. Tomalia, H. Baker, J.R. Dewald, M. Hall, G. Kallos, S. Martin, J. Roeck, J. Ryder, P. Smith, Dendrimers II: architecture, nanostructure and supramolecular chemistry, Macromolecules 19 (1986) 2466-2468.

[17] G.R. Newkome, Z.-Q. Yao, G.R. Baker, K.J. Gupta, Cascade molecules: a new approach to micelles, A [27]-arborol, J. Org. Chem. 50 (1985) 2003-2006.

[18] P.K. Baker, M.B. Hursthouse, A.I. Karaulov, A.J. Lavery, K.M.A. Malik, D.J. Muldoona, A. Shawcross, Seven-co-ordinate dibromo complexes of molybdenum(II) and tungsten(II) derived from $\left[\mathrm{MBr}_{2}(\mathrm{CO})_{3}(\mathrm{NCMe})_{2}\right]$. Crystal structures of the lsostructural complexes $\left[\mathrm{WX}_{2}(\mathrm{CO})_{3}(\mathrm{NCMe})\left(\mathrm{SbPh}_{3}\right)\right] \cdot \mathrm{CH}_{2} \mathrm{Cl}_{2}$
(X = Br or I), J. Chem. Soc. Dalton Trans. (1994) 3493-3498.

[19] P.K. Baker, S.G. Fraser, E.M. Keys, The synthesis and spectral properties of some highly reactive new seven-coordinate molybdenum(II) and tungsten(II) bisacetonitrile dihalogenotricarronyl complexes, J. Organomet. Chem. 309 (1986) 319-321.

[20] C.D. Nunes, M. Pillinger, A.A. Valente, J. Rocha, A.D. Lopes, I.S. Gonçalves Dioxomolybdenum(VI)-Modified mesoporous MCM-41 and MCM-48 materials for the catalytic epoxidation of olefins, Eur. J. Inorg. Chem. 2003 (2003) 3870-3877.

[21] M.V. Dias, M.S. Saraiva, P. Ferreira, M.J. Calhorda, Catalytic activity of molybdenum(II) complexes in homogeneous and heterogeneous conditions, Organometallics 34 (2015) 1465-1478.

[22] C.J. Brinker, G.W. Scherer, Sol-gel Science: the Physics and Chemistry of Solgel Processing, Academic Press, Boston, 1990.

[23] J.D. Wright, N.A.J.M. Sommerdijk, Sol-gel Materials: Chemistry and Applications, CRC Press, Boca Raton, 2001.

[24] M.C. Mattos, L. Marzorati, Michael addition. Mechanistic aspects, Quím. Nova 22 (1999) 710-714.

[25] E.G. Vieira, R.O. Silva, A.G. Dal-Bó, T.E.A. Frizon, N.L. Dias Filho, Syntheses and catalytic activities of new metallodendritic catalysts, New J. Chem. 40 (2016) 9403-9414.

[26] R.M. Silverstein, F.X. Webster, D.J. Kiemle, Spectrometric Identification of Organic Compounds, 7rd edn., John Wiley \& Sons-Inc, 2005.

[27] P.K. Baker, The organometallic chemistry of halocarbonyl complexes of molybdenum (II) and tungsten (II), Adv. Organomet. Chem. 40 (1996) 45-115.

[28] A.J. Waddon, E.B. Coughlin, Crystal structure of polyhedral oligomeric silsequioxane (POSS) nano-materials: a study by X-ray diffraction and electron microscopy, Chem. Mater 15 (2003) 4555-4561.

[29] A. Arkhireeva, J.N. Hay, Synthesis of sub-200 mn silsesquioxane particles using a modified Stober sol-gel route, J. Mater. Chem. 12 (2003) 3122-3127.

[30] R. Qu, C. Sun, F. Ma, Z. Cui, Y. Zhang, X. Sun, C. Ji, C. Wang, P. Yin, Adsorption kinetics and equilibrium of copper from ethanol fuel on silica-gel functionalized with amino-terminated dendrimer-like polyamidoamine polymers, Fuel 92 (2012) 204-210.

[31] R. Ahmad, R. Kumar, Adsorptive removal of Congo red dye from aqueous solution using bael shell carbon, Appl. Surf. Sci. 257 (2010) 1628-1633.

[32] E.G. Vieira, I.V. Soares, G. Pires, R.A.V. Ramos, D.R. do Carmo, N.L. Dias Filho Study on determination and removal of metallic ions from aqueous and alcoholic solutions using a new POSS adsorbent, Chem. Eng. J. 264 (2015) 77-88.

[33] H.M.F. Freundlich, Uber die adsorption in Losungen, Z. Phys. Chem. 57 (1906) $358-385$.

[34] R. Ahmad, R. Kumar, Adsorptive removal of Congo red dye from aqueous solution using bael shell carbon, Appl. Surf. Sci. 257 (2010) 1628-1633.

[35] I. Langmuir, The adsorption of gases on plane surfaces of glass, mica and platinium, J. Am. Chem. Soc. 40 (1918) 1361-1403.

[36] N.L. Dias Filho, F. Marangoni, R.M. Costa, Preparation, characterization, and $\mathrm{CuX}_{2}$ and $\mathrm{CoX}_{2}\left(\mathrm{X}=\mathrm{Cl}^{-}, \mathrm{Br}^{-}, \mathrm{ClO}^{-4}\right)$ adsorption behavior of a polyhedral oligomer silsesquioxane functionalized with an organic base, J. Colloid Interf. Sci. 313 (2007) 34-40.

[37] M.J. Temkin, V. Pyzhev, Recent modifications to Langmuir isotherms, Acta Physiochim. 12 (1940) 217-222.

[38] M.M. Dubinin, E.D. Zaverina, L.V. Radushkevich, Sorption and structure of active carbons I. Adsorption of organic vapors, Zh. Fiz. Khim 21 (1947) 1351-1362.

[39] M. Ozacar, I.A. Sengil, Adsorption of reactive dyes on calcined alunite from aqueous solutions, J. Hazard. Mater 98 (2003) 211-224.

[40] Y.S. Ho, G. McKay, Application of kinetic models to the sorption of copper (II) on to peat, Adsorpt. Sci. Technol. 20 (2002) 795-817.

[41] M. Ozacar, I.A. Sengil, A kinetic study of metal complex dye sorption onto pine sawdust, Process Biochem. 40 (2005) 565-572.

[42] F. Semnani, Z. Asadi, M. Samadfam, H. Sepehrian, Uranium(VI) sorption behavior onto amberlite CG-400 anion exchange resin: effects of $\mathrm{pH}$, contact time, temperature and presence of phosphate, Ann. Nucl. Energy 48 (2012) $21-24$.

[43] J.C. Alonso, P. Neves, M.J. Pires da Silva, S. Quintal, P.D. Vaz, C. Silva, A.A. Valente, P. Ferreira, M.J. Calhorda, V. Felix, M.G.B. Drew, Molybdenum $\eta^{3}-$ Allyl dicarbonyl complexes as a new class of precursors for highly reactive epoxidation catalysts with tert-butyl hydroperoxide, Organometallics 26 (2007) 5548-5556.

[44] S. Halder, A. Mukherjee, K. Ghosh, S. Dey, M. Nandi, P. Roy, Synthesis, characterization and catalytic activities towards epoxidation of olefins of dinuclear copper(II) complexes, J. Mol. Struct. 1101 (2015) 1-7.

[45] Z. Asgharpour, F. Farzaneh, A. Abbasi, M. Ghiasi, Synthesis, crystal structure and DFT studies of a new dioxomolybdenum (VI) Schiff base complex as an olefin epoxidation catalyst, Polyhedron 101 (2015) 282-289.

[46] Z. Wang, S. Li, W.J. Teo, Y.T. Poh, J. Zhao, T.S.A. Hor, Molybdenum (0) and tungsten (0) carbonyl N-heterocyclic carbene complexes as catalyst for olefin epoxidation, J. Organomet. Chem. 775 (2015) 188-194.

[47] A. Schmidt, N. Grover, T.K. Zimmermann, L. Graser, M. Cokoja, A. Pöthig, F.E. Kühn, Synthesis and characterization of novel cyclopentadienyl molybdenum imidazo[1,5-a]pyridine-3-ylidene complexes and their application in olefin epoxidation catalysis, J. Catal. 319 (2014) 119-126. 